\title{
LETTERS
}

\section{Challenging research assumptions from an Indigenous perspective}

Given the disparities in health outcomes for Indigenous populations in Canada, He and colleagues'1 work into infant morbidities in Quebec populations is an important contribution to the understanding of the problem. The sizable cohort allowed for good comparison between Indigenous and non-Indigenous populations and there was recognition of the disparity in resource allocation and living conditions. However, several assumptions were made in the article that should be viewed and challenged from an Indigenous perspective.

The first of these is the assumption that an unmarried Indigenous mother, living on reserve, is living alone. Culturally, a young woman would live with and have the support of her extended family, and a shortage of housing on reserves eliminates the option of living alone. These shortages contribute to the quality of the living environment, and substantially more First Nations peoples live in overcrowded homes than non-Indigenous Canadians: $27 \%$ versus $4 \%{ }^{2}$

Second, the article states that the leading causes of illness are infection and respiratory diseases. He and colleagues deduce that the disparities (of infection and respiratory disease rates) are preventable, acknowledging the substandard living conditions and high smoking rates among many First Nation populations. The article goes on to highlight immunization programs and breastfeeding as factors that could be improved to address the increased risks of infections and respiratory diseases. However, the evidence does not support these factors as contributors to health disparities related to Indigenous infant morbidity. A British Columbia review of Indigenous breastfeeding rates found that Indigenous women in BC breastfeed at a higher rate and for longer periods than the general Canadian population. ${ }^{3}$ Health Canada does not monitor immunization rates on reserve, but an evaluation of Indigenous health from 2008 to 2012 suggests that Indigenous immunization rates are increasing. It found that $80 \%$ of twoyear-old children on reserve received the measles, mumps and rubella vaccine during the review period, a rate slightly lower than the Canadian average. ${ }^{4}$

Most concerning in this paper was the perpetuation of the false assumption that Indigenous peoples consume alcohol at a higher rate than non-Indigenous Canadians. Drinking rates on reserve are nearly half those of non-First Nations peoples, and only $40 \%$ of Indigenous youth report having consumed alcohol, compared with $76 \%$ of non-Indigenous Canadian youth. ${ }^{5}$ The 2015 report by the Chief Public Health Officer of Canada finds that among adults, the rate of heavy drinking is reported by $22.5 \%$ of non-Indigenous peoples and $32.7 \%$ of off-reserve Indigenous Canadians. However, the 2016 report found that $20 \%$ of Indigenous youth report drinking heavily (the consumption of four or more drinks for females and five or more for males on a single occasion), whereas more than $46 \%$ of nonIndigenous youth report binge drinking (the consumption of four or more drinks in a single sitting). ${ }^{4}$

This article's focus on the disparities in infant morbidity is an important conversation that must happen as we move toward reducing the health gap in Canada. It also raises red flags that are not unique to this article or these authors. Researchers must look past the historical biases so often couched within earlier studies and challenge themselves to identify and question their own perceptions of Indigenous health and the causes of their health disparities.

\section{Sheryl Thompson BA(Hons) Candidate}

Student, Simon Fraser University, Burnaby, BC

Cite as: CMAJ 2018 October 15;190: E1233. doi: 10.1503/cmaj.70181

\section{References}

1. He H, Xiao L, Torrie JE et al. Disparities in infant hospitalizations in Indigenous and non-Indigenous populations in Quebec, Canada. CMAJ 2017 May 29;189:E739-46.

2. Aboriginal statistics at a glance: 2 nd ed. Housing conditions. Ottawa: Statistics Canada; 2011. Cat no 89-645-X. Available: www.statcan.gc.ca/pub/ 89-645-x/2015001/housing-logement-eng.htm (accessed 2018 May 30).

3. Strong women, strong nations: Aboriginal maternal health in British Columbia. Prince George (BC): National Collaborating Centre for Aboriginal Health; 2014.

4. Immunization. What is influencing our health? In: Health status of Canadians 2016: report of the Chief Public Health Officer. Ottawa: Public Health Agency of Canada; 2016.

5. The Chief Public Health Officer's report on the state of public health in Canada 2015: Alcohol consumption in Canada. Ottawa: Public Health Agency of Canada; 2015

6. Burnside L, Fuchs D. Presence of fetal alcohol spectrum disorder: a literature review. A triprovince initiative to expand understanding of costs, services \& prevention of a public prevalence of fetal alcohol spectrum disorder; 2011. Available: www.fasdchildwelfare.ca/sites/default/files/ research/Ap25\%2003a\%20PHAC\%20FASD\%20 Prevalence\%20Lit\%20Review\%20FINAL\%202011. pdf (accessed May 16, 2018).

Competing interests: None declared. 